\title{
Synthetic, Functional Thymidine-Derived Polydeoxyribonucleotide Analogues from a Six-Membered Cyclic Phosphoester
}

\author{
Yi-Yun Timothy Tsao and Karen L. Wooley*i] \\ Departments of Chemistry, Chemical Engineering, Materials Science \& Engineering, and The Laboratory for Synthetic-Biologic \\ Interactions, Texas A\&M University, College Station, Texas 77842-3012, United States
}

\section{Supporting Information}

\begin{abstract}
A grand challenge that crosses synthetic chemistry and biology is the scalable production of functional analogues of biomacromolecules. We have focused our attention on the use of deoxynucleoside building blocks bearing non-natural bases to develop a synthetic methodology that allows for the construction of high molecular weight deoxynucleotide polymers. Our six-membered cyclic phosphoester ring-opening polymerization strategy is demonstrated, herein, by an initial preparation of novel polyphosphoesters,

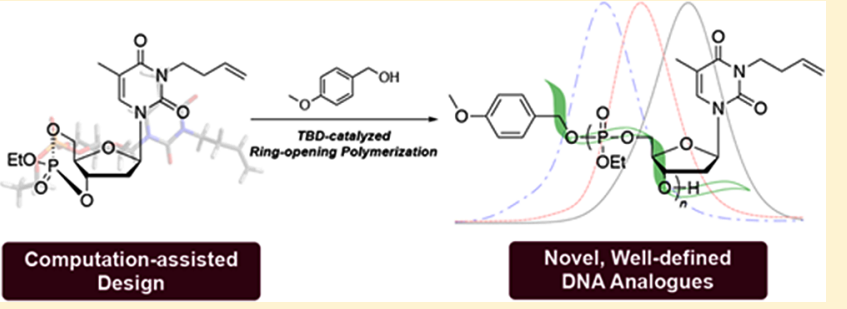
comprised of butenyl-functionalized deoxyribonucleoside repeat units, connected via $3^{\prime}, 5^{\prime}$-backbone linkages. A thymidinederived bicyclic monomer, $3^{\prime}, 5^{\prime}$-cyclic 3-(3-butenyl) thymidine ethylphosphate, was synthesized in two steps directly from thymidine, via butenylation and diastereoselective cyclization promoted by $N, N$-dimethyl-4-aminopyridine. Computational modeling of the six-membered $3^{\prime}, 5^{\prime}$-cyclic phosphoester ring derived from deoxyribose indicated strain energies at least $5.4 \mathrm{kcal} /$ mol higher than those of the six-membered monocyclic phosphoester, 2-ethoxy-1,3,2-dioxaphosphinane 2-oxide. These calculations supported the hypothesis that the strained $3^{\prime}, 5^{\prime}$-cyclic monomer can promote ring-opening polymerization to afford the resulting poly $\left(3^{\prime}, 5^{\prime}\right.$-cyclic 3-(3-butenyl) thymidine ethylphosphate)s with low dispersities $(\nexists<1.10)$. This advanced design combines the merits of natural product-derived materials and functional, degradable polymers to provide a new platform for functional, synthetically derived polydeoxyribonucleotide-analogue materials.
\end{abstract}

\section{INTRODUCTION}

Nucleosides play important roles in Nature. ${ }^{1}$ The incorporation of non-natural nucleosides into DNA and RNA allows for significant investigations, including fundamental research on structure and function, ${ }^{2-8}$ and development of synthetic materials for clinical applications; ${ }^{9-11}$ yet there are only few routes that allow access to well-defined synthetic DNA and RNA derivatives. Enzymatic processes that integrate nonnatural nucleosides into DNA and RNA are limited by the activity of the mediating polymerase, which often restricts the extent of incorporation and reaction conditions. ${ }^{12-15}$ On the other hand, synthetic methods offer exquisite sequence control, but have focused mainly on stepwise condensation reactions of nucleoside repeat units with electrophiles, such as $3^{\prime}$ phosphoryl chloride, ${ }^{16}$ phosphotriester, ${ }^{17,18}$ and phosphoramidites $^{19}$ (e.g., via solid-phase DNA synthesis). Synthetic methods have not yet advanced for the construction of nucleic acid-based polymers having $3^{\prime}, 5^{\prime}$-linkages through controlled chain-growth addition polymerization, which offers rapid and convenient polymer chain growth. Currently, syntheses of DNA-derived polymers ${ }^{20}$ by chain-growth chemistries remain limited to non-3',5'-backbones through uncontrolled radical polymerization, ${ }^{21,22}$ atom transfer radical polymerization (ATRP), ${ }^{23-25}$ and reversible addition-fragmentation chain transfer (RAFT) polymerization ${ }^{26}$ techniques that yield polymers with pendant nucleosides. For $3^{\prime}, 5^{\prime}$-DNA-derived materials, polymerization with predetermined molar mass and control over end groups and sequence is a feasible, yet unrealized, aim.

Besides several well-known polymer classes used in biological research, such as polyesters and polycarbonates, polyphosphoesters, and particularly nucleoside phosphoesters, ${ }^{27}$ are attractive due to their biocompatibility, biodegradability through spontaneous and/or enzymatic hydrolysis, as well as their structural similarity to nucleic and teichoic acids. ${ }^{28}$ Ringopening polymerization (ROP) is a versatile synthetic method for generating well-defined macromolecules from carbocyclic or heterocyclic monomers, ${ }^{29,30}$ and organocatalytic $\mathrm{ROP}^{31-38}$ of five-membered cyclic phosphoesters has been demonstrated to produce well-defined polyphosphoesters. ${ }^{28,33,39}$ However, polymerization of six-membered cyclic phosphorus-containing monomers, a potential precursor for well-defined DNA analogues with $3^{\prime}, 5^{\prime}$-backbones, has received less attention. Studies on the ROP of a six-membered phosphorinane monomer, 2-hydro-2-oxo-1,3,2-dioxaphosphorinane, have been reported by Penczek and co-workers. ${ }^{40-42}$ Polymerization was possible due to tautomerization of the monomer to generate phosphorus(III) intermediates in situ ${ }^{43}$ that provide a less sterically hindered environment at the electrophilic

Received: February 1, 2017

Published: April 10, 2017 
phosphorus center. Such ROPs have not yet been fully expanded to nontautomerizable six-membered cyclic phosphoesters, such as cyclic adenosine monophosphate (cAMP) and its guanosine counterpart (cGMP), which play critical metabolic and regulatory roles. The only report on the ROP of a nontautomerizable six-membered phosphorinane, 2-methoxy2-oxo-1,3,2-dioxaphosphorinane, led to oligomers (degree of polymerization $\leq 10$ ) under harsh conditions (neat, $135{ }^{\circ} \mathrm{C}$ ), due to extensive chain transfer originating from the low ring strain energy. ${ }^{44}$ Hence, to achieve higher molecular weight polyphosphoesters from six-membered cyclic phosphoesters, introducing ring strain energy into the cyclic system is critical.

Higher ring strain energy is also generally accepted to be the key factor that facilitates the polymerization of five-membered cyclic phosphoesters. The hydrolysis rates of five-membered cyclic phosphoesters increase by an order of $10^{5}$ as compared to the acyclic species, which were attributed to enthalpy of activation, ${ }^{45} \Delta H^{\ddagger}$, rather than to the entropy of activation, ${ }^{46}$ $\Delta S^{\ddagger}$, according to Eyring plots. Ring strain and its relief are enthalpic phenomena, and, hence, we reasoned that, if relief of ring strain in the transition state of the rate-determining step is crucial to the acceleration of hydrolysis in the cyclic phosphoesters, analysis of those ring strain energies could guide monomer design.

Herein, we report a synthetic strategy that includes organocatalytic ROP of a six-membered cyclic phosphoester monomer at ambient temperature to afford a new type of thymidine-derived 3',5'-linked polyphosphoester with a butenyl group located on each repeat unit and number-average molecular weights $\left(M_{\mathrm{n}}\right)$ up to $11 \mathrm{kDa}$. The monomer was prepared in two steps, and the polymerization proceeded in a controlled fashion to afford polymers with low dispersities $(\boxplus)$. This Article focuses on the synthesis of the novel monomers and polymers that comprise a thymidine DNA derivative with a polyphosphoester backbone. To the best of our knowledge, no well-defined DNA-derived polyphosphoesters with $3^{\prime}, 5^{\prime}$-linkages in the backbones from ROP have been reported to date.

\section{RESULTS AND DISCUSSION}

The ring strain energies of monocyclic five-membered, monocyclic six-membered, and $3^{\prime}, 5^{\prime}$-cyclic phosphoesters were calculated using density functional theory (DFT). The theoretical estimation of ring strain energies serves as computational insight into direct the rational design of $3^{\prime}, 5^{\prime}$ cyclic phosphoesters in nucleosides as a skeleton for ROP of six-membered cyclic phosphoesters. Ring strain energy is a relative quantity and is defined as the excess energy between a cyclic molecule and an appropriately selected strain-free, linear counterpart. Theoretical estimates of ring strain energy can be obtained by using group equivalents to convert DFT energies into reasonably accurate heats of formation. To investigate the feasibility of ROP of $3^{\prime}, 5^{\prime}$-cyclic phosphoesters, ring strain energies of different cyclic phosphoesters (Figure 1a) were calculated with DFT using an approach similar to a previous report by the Lim group ${ }^{47}$ at the B3LYP/6-31+G*, B97-D/6$31+\mathrm{G}^{*}$, and $\mathrm{M} 06-2 X / 6-31+\mathrm{G}^{*}$ levels of theory to include adjustments for medium-range electron and dispersion corrections (Table 1). With the six-membered cyclic phosphoester 1 assumed to be unstrained, the validity of DFT calculations was verified by comparing the calculated ring strain energies of 2 to experimental values. ${ }^{48}$ While a systematic study on the ring strain energy of the $3^{\prime}, 5^{\prime}$-cyclic system was not reported, enthalpies of hydrolysis of cAMP and diethyl a
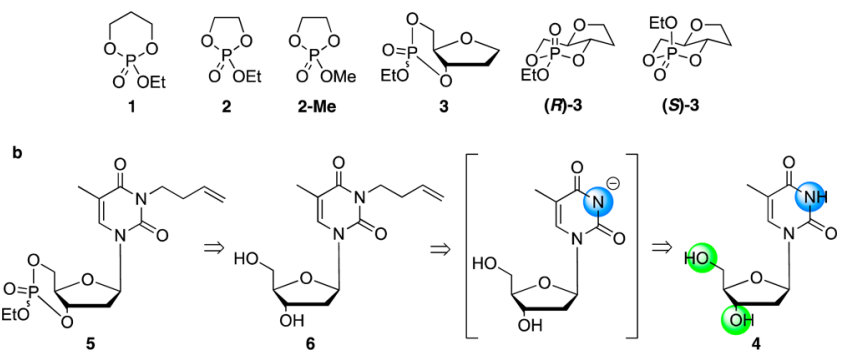

Figure 1. Design and retrosynthesis of thymidine-derived DNA analogues. (a) Different cyclic phosphoesters for DFT calculation of ring strain energies. (b) Retrosynthetic analysis of the cyclic monomer 4 from thymidine 6 .

Table 1. Experimental and DFT Calculations of the Ring Strain Energies (kcal/mol) of Six-Membered Cyclic Phosphoester (1), Five-Membered Cyclic Phosphoester (2), and $3^{\prime}, 5^{\prime}$-Cyclic Phosphoester (3)

\begin{tabular}{ccccc} 
method & $\mathbf{1}$ & $\mathbf{2}$ & $(\boldsymbol{R})-\mathbf{3}$ & $(\boldsymbol{S})-\mathbf{3}$ \\
\hline experimental & & $5.9 \pm 0.3^{a}$ & & \\
$\mathrm{~B} 3 \mathrm{LYP} / 6-31+\mathrm{G}^{a}$ & 0 & 4.1 & 6.3 & 5.9 \\
$\mathrm{M} 06-2 \mathrm{X} / 6-31+\mathrm{G}^{a}$ & 0 & 5.0 & 7.2 & 5.4 \\
B97-D/6-31+G $^{a}$ & 0 & 4.2 & 7.0 & 5.8 \\
${ }^{a}$ Experimental value of 2-Me was reported. & \\
\end{tabular}

phosphate, $11.49 \pm 0.35$ and $2.50 \pm 0.45 \mathrm{kcal} / \mathrm{mol}$, respectively, ${ }^{49}$ suggest a large ring strain energy for the $3^{\prime}, 5^{\prime}$ cyclic system and are in agreement with the calculation results. Therefore, it was expected that the higher ring strain energy of the designed $3^{\prime}, 5^{\prime}$-cyclic phosphoester 3 would allow for ROP on a six-membered cyclic phosphoester under mild conditions. Moreover, the diastereomer (R)-3 was found to be more strained, due to the anomeric effect in $(S)-3 .^{50-54}$

To construct a $3^{\prime}, 5^{\prime}$-cyclic system similar to 3 , thymidine (4) was chosen of the four natural deoxyribonucleosides, due to the potential for selective functionalization at the $3^{\prime}-\mathrm{OH}, 5^{\prime}-\mathrm{OH}$, and $N^{3}$-positions. Selective functionalization at the $N^{3}$-position can be achieved with weak bases, such as potassium carbonate, given the $\mathrm{p} K_{\mathrm{a}}$ differences between alcohols $\left(\mathrm{p} K_{\mathrm{a}} \approx 16-17\right)$ and the $N^{3}$-proton $\left(\mathrm{p} K_{\mathrm{a}} \approx 9.5\right) .{ }^{20}$ In contrast, strong bases, such as sodium hydride, have the capability to deprotonate the $3^{\prime}-\mathrm{OH}$, $5^{\prime}-\mathrm{OH}$, and $\mathrm{N}^{3}$-protons, with functionalization occurring preferentially at the $3^{\prime}-\mathrm{OH}$ and $5^{\prime}-\mathrm{OH}$ positions, due to the increased nucleophilicity of alkoxides over imide anions. The standard retrosynthetic analysis for the target monomer, 5, a strained $3^{\prime}, 5^{\prime}$-cyclic structure, is given in Figure $1 \mathrm{~b}$. The synthesis was realized through a two-step procedure that involved selective butenylation at the $N^{3}$-position in the presence of weak base, followed by cyclization of $3^{\prime}-\mathrm{OH}$ and $5^{\prime}-\mathrm{OH}$.

Installation of a butenyl group at $N^{3}$ was conducted to coincidentally protect the imide, enhance organic solubility, and install a functionality that would allow for later chemical modification. Because of the two electron-withdrawing carbonyl groups at the 2-and 4-positions of the thymine unit, chemical modification via nucleophilic substitution to afford $\mathrm{N}^{3}$ substituted thymidine typically requires several days for completion. Choice of solvents is also limited, due to the solubility of the thymidine starting material, 4 . Butenylation at the $\mathrm{N}^{3}$-position was found to be possible in $N, N$-dimethylformamide (DMF) at $60{ }^{\circ} \mathrm{C}$ to give 6 as a white hygroscopic solid 
Table 2. Condition Screening for Cyclization of 6 with 7 Using Various Solvents and Bases at $-78{ }^{\circ} \mathrm{C}$

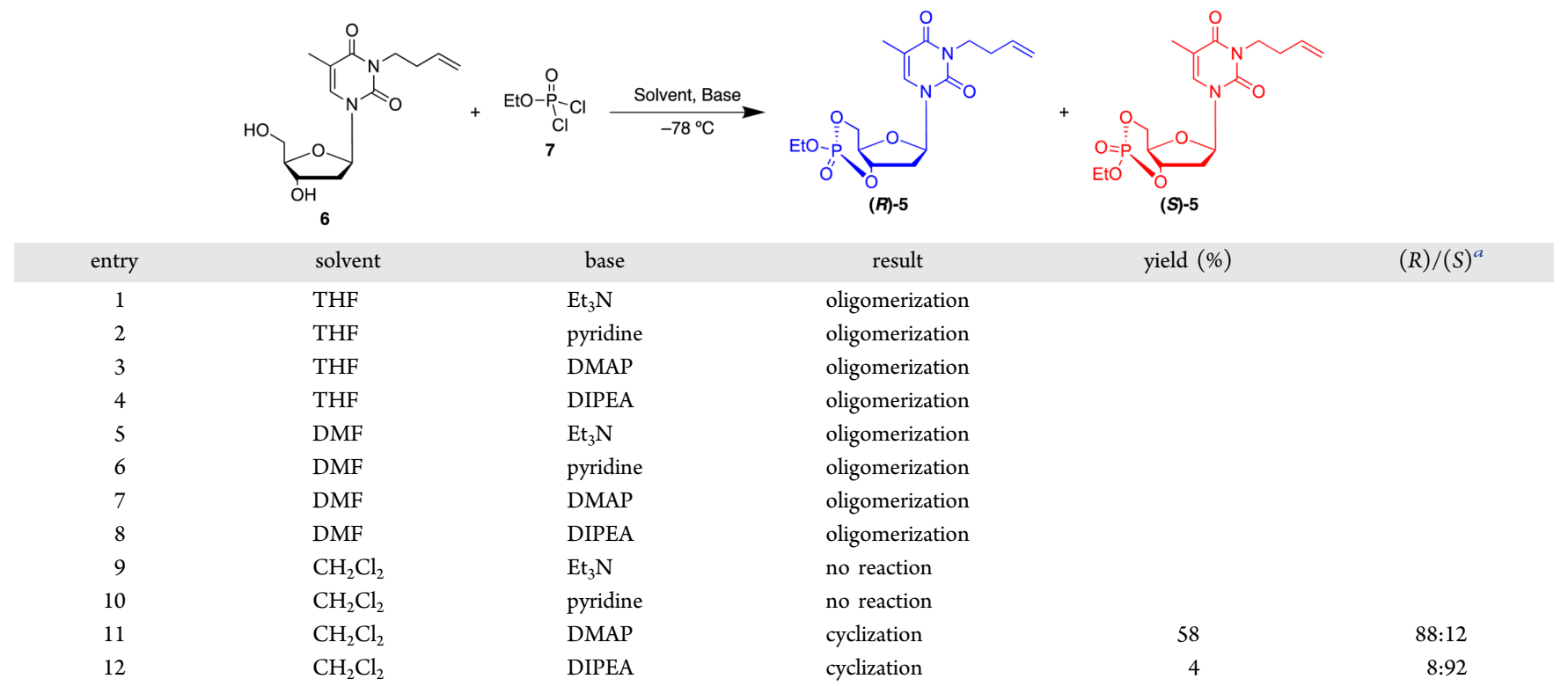

${ }^{a}(R) /(S)$ ratio was determined by ${ }^{31} \mathrm{P}$ NMR of reaction crude.

with high yields $(>90 \%)$ within $48 \mathrm{~h}$, while reaction in methanol under the same conditions required longer reaction times (at least $96 \mathrm{~h}$ ).

A key challenge in the second step of the synthetic approach is to favor cyclization over oligomerization. Cyclization of $\mathbf{6}$ was expected to be both kinetically and thermodynamically difficult, given the large ring strain barrier as well as slow kinetics of cyclizing a trans-diol, which is in agreement with results from the Buchard group. ${ }^{55,56}$ A linear oligomer was obtained upon reaction with ethyl dichlorophosphate (7), in the presence of triethylamine in tetrahydrofuran (THF) under dilute conditions. Sufficient time for the conformational change from the intermediate (8) was hypothesized to be important, to bring the second alcohol and phosphorus into proximity to close the ring, versus bimolecular reactions that could lead to oligomerization. Additionally, it was considered that weaker leaving groups might slow the condensation reaction, and 4nitrophenol has been shown to be a moderate leaving group for phosphoester cleavage in the presence of an activator. ${ }^{57}$ Jain and Kalman have reported the use of 4-nitrophenol and 1,8diazabicyclo[5.4.0] undec-7-ene (DBU) as leaving group and activator, respectively, to cyclize 5-fluoro- 2 '-deoxyuridine. ${ }^{58}$ However, attempts at ring closure by reaction of 6 with ethyl bis(4-nitrophenyl)phosphate encountered the challenge of incomplete separation of the monomer from the byproduct 4-nitrophenol, which could be a deactivator of the organocatalyst for ROP. Cyclization conditions were then screened with the aim of optimizing the cyclization reaction using ethyl dichlorophosphate (Table 2).

Oligomerization occurred when the reactions were conducted in DMF and THF, in the presence of a variety of bases. Polar aprotic solvents, such as DMF and THF, were found to promote oligomerization over cyclization, presumably by shortening the lifetime of the intermediate (8). The bases 4dimethylaminopyridine (DMAP) and $N, N$-diisopropylethylamine (DIPEA) effectively facilitated cyclization in dichloromethane. Interestingly, the diastereoselectivity of these two reactions differed significantly, where DMAP and DIPEA yielded $(R):(S)$ ratios of $88: 12$ and $8: 92$, respectively. This selectivity is attributed to the nucleophilic characteristic of DMAP to activate 7 and yield a more stable transition state that leads to kinetic product $(R)-5$, even though $(S)-5$ is more stable by $1.35 \mathrm{kcal} / \mathrm{mol}$ at the B3LYP/6-31+G* level of theory (Scheme 1 and Figure 2). Because several recrystallization

Scheme 1. Synthetic Route from Thymidine to Monomer 5
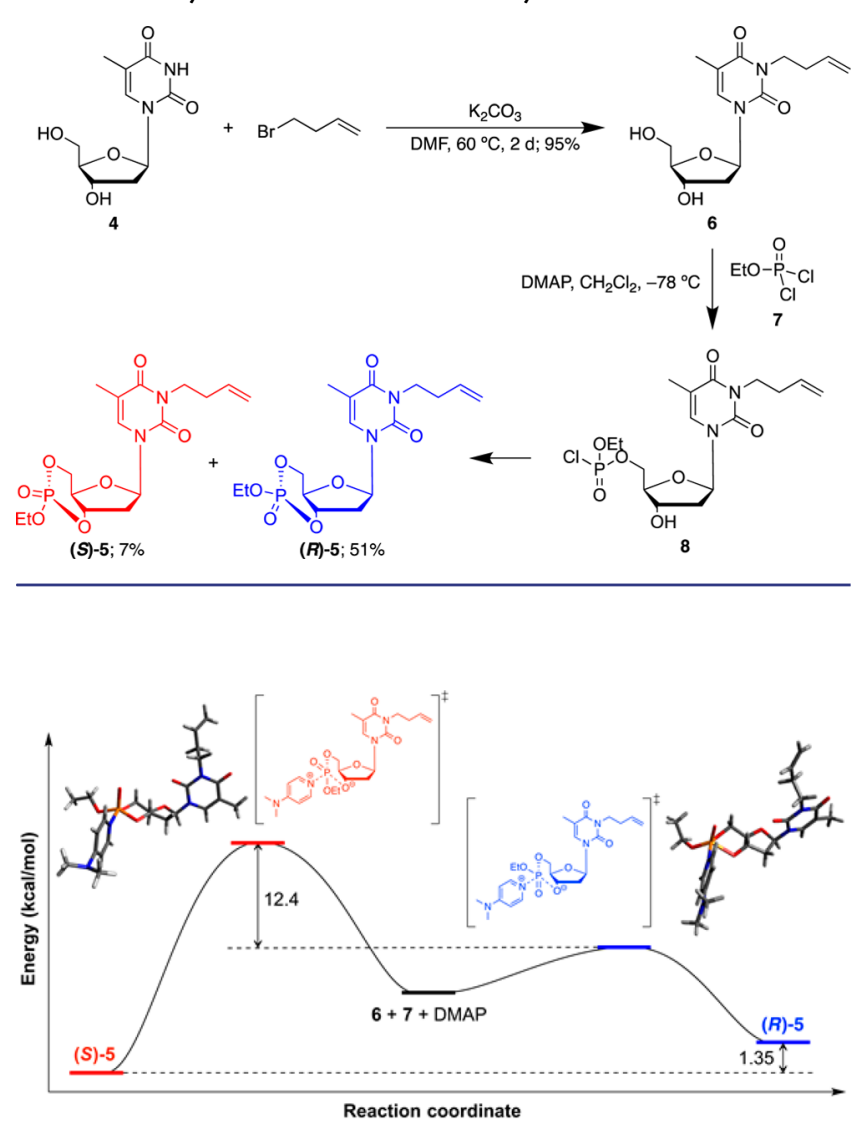

Figure 2. Reaction coordinate diagram of using DMAP as activator to promote cyclization of 6 at the B3LYP/ $6-31+\mathrm{G}^{*}$ level of theory. 


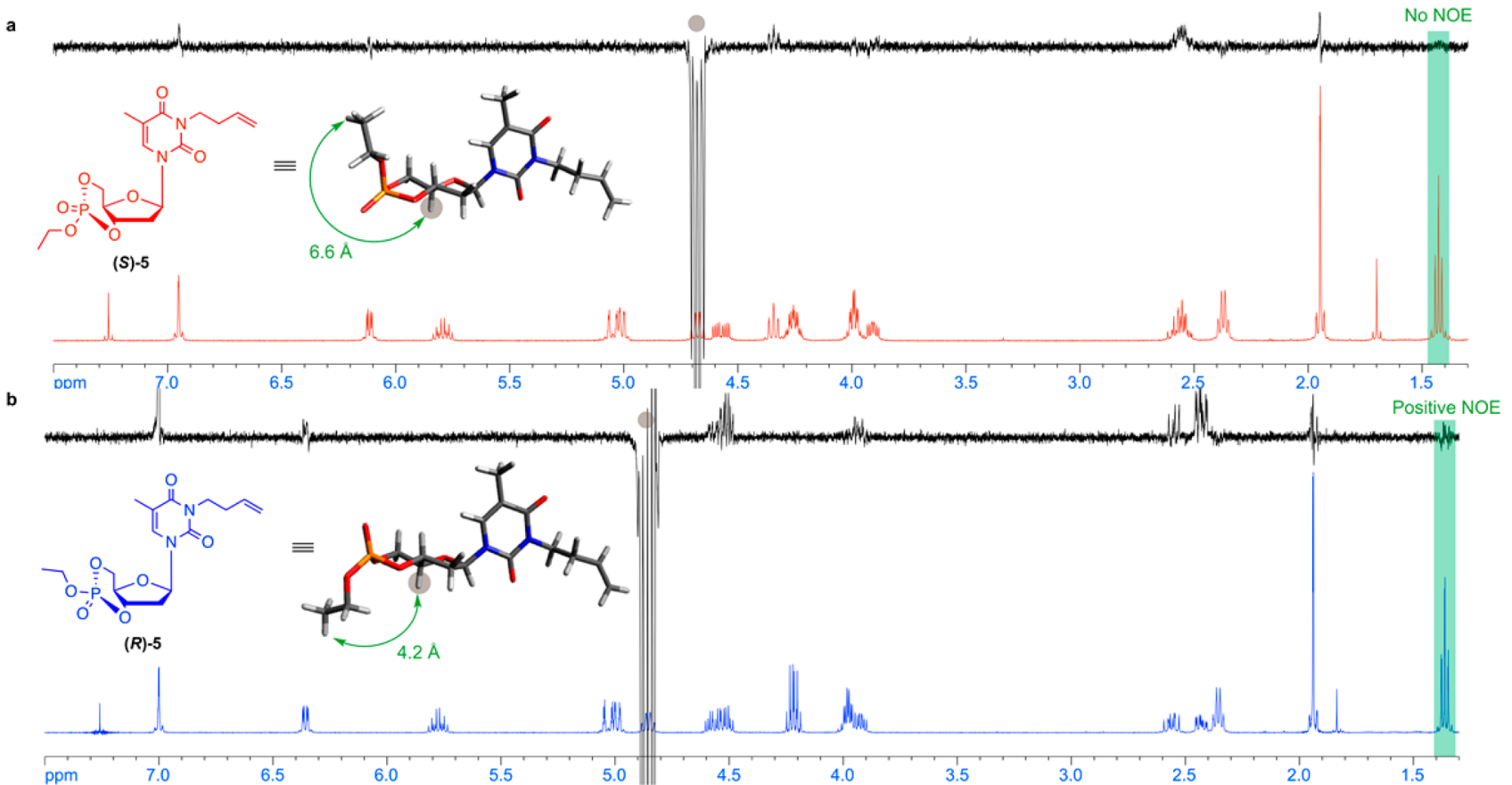

Figure 3. Use of 1D-NOESY to identify the diastereomers (a) (S)-5 and (b) (R)-5, with atomic distances of 6.6 and $4.2 \AA$, respectively, calculated from DFT geometric optimization at the B $3 \mathrm{LYP} / 6-31+\mathrm{G}^{*}$ level of theory.

conditions failed to obtain a single crystal of $\mathbf{5}$ for X-ray diffraction measurement, the absolute stereochemistries were then determined by an indirect method with one-dimensional nuclear Overhauser spectroscopy (1D-NOESY). The throughspace atomic distances between $4^{\prime}-\mathrm{H}$ (marked in gray on the structures in Figure 3) and the methyl protons of the ethyl phosphoester in the diastereomeric pairs are sufficiently different, 6.6 versus $4.2 \AA$ for $(S)-5$ versus $(R)-5$, respectively, that the diastereomer assignments could be made by a positive NOE only for the (R)-diastereomer in the 1D-NOESY experiment.

ROP of 5 was conducted using 1,5,7-triazabicyclo[4.4.0] dec5-ene (TBD) as the catalyst, and 4-methoxybenzyl alcohol, a natural chemical found in anise, honey, and vanilla, as the initiator to enable straightforward end-group analysis by NMR and to minimize potential toxicity following hydrolytic degradation (Scheme 2). ROP of (R)-5 initiated at the onset of TBD addition, according to thin-layer chromatography. In contrast, the diastereomer $(S)-5$ showed no reaction under the same conditions after $96 \mathrm{~h}$; this lower reactivity is in agreement with the lower ring strain energy calculated for the $(S)$ configuration (Table 1$)$. Attempts to polymerize $(S)-5$ at lower temperatures $\left(0\right.$ and $\left.-78{ }^{\circ} \mathrm{C}\right)$, to suppress the entropic penalty, were unsuccessful. The conversion of $(\boldsymbol{R})-5$ monomer to afford $\operatorname{poly}\left(3^{\prime}, 5^{\prime}\right.$-cyclic 3-(3-butenyl) thymidine ethylphosphate) (PCBT, 9) reached over 95\% at ambient temperature, with good control of the polymerization being retained, as suggested by low $Ð$ and excellent linear agreement between the $M_{\mathrm{n}}$ and percent monomer conversion (Figures 4 and 5 and Table 3 ). Copolymerization of a 88:12 diastereomeric mixture of $(\boldsymbol{R})-\mathbf{5}$ : (S)-5 monomers led to incomplete copolymerization, without apparent incorporation of $(S)-\mathbf{5}$, as indicated by the proportion of polymer to remaining $(R)-5$ and $(S)-5$ unreacted monomers being 86:2:12, according to the crude ${ }^{31} \mathrm{P}$ NMR spectrum (Figure S7). ${ }^{13} \mathrm{C}$ and ${ }^{31} \mathrm{P}$ NMR spectra of PCBT 10, PCBT $_{21}$, and $\mathbf{P C B T}_{32}$ contained signals resonating at multiple
Scheme 2. Polymerization of 5 with 4-Methoxybenzyl Alcohol as the Initiator and TBD as the Catalyst ${ }^{a}$

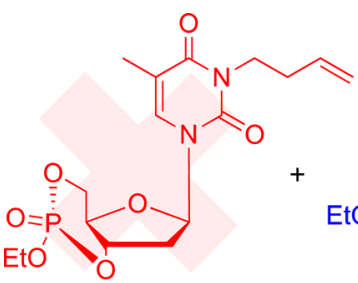

(S)-5

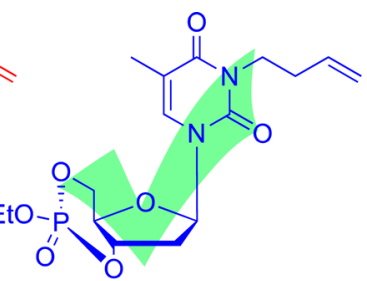

(R)-5

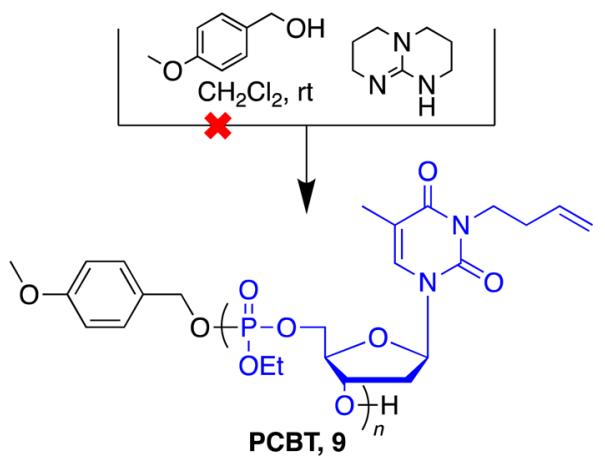

${ }^{a}$ Although the polymer is illustrated with only one regiochemistry and no stereochemistry, ${ }^{31} \mathrm{P}$ NMR spectra suggested that the polymers contained regioisomeric and diastereoisomeric repeat units.

frequencies, which may have resulted from diastereomers and, potentially, combinations of head-to-head, head-to-tail, and tailto-tail regioisomers (Figures S4-S6). Regioisomeric differences are possible from cleavage of the $\mathrm{P}-\mathrm{O}^{\prime}$ versus $\mathrm{P}-\mathrm{O}^{\prime}$ bond during the initial ring opening following attack by an initiator, and also during subsequent ring openings during propagation of the ROP. A model reaction employing excess ethanol as initiator and solvent was conducted to prevent the formation of diastereomeric products and allow for evaluation of the 


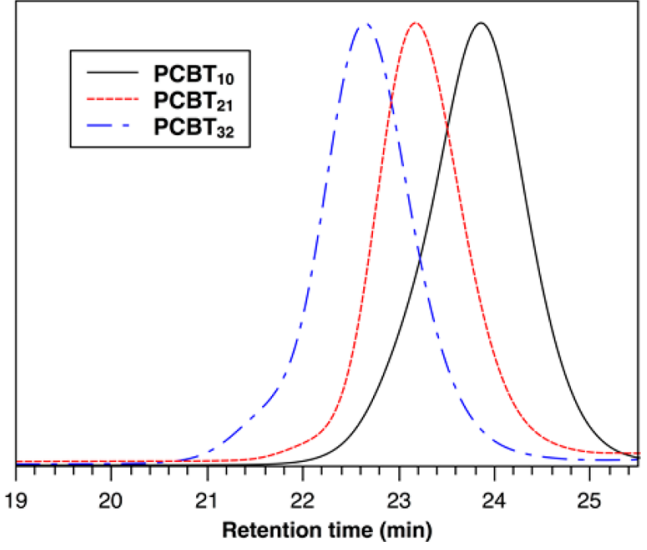

Figure 4. SEC traces of $\mathrm{PCBT}_{10}, \mathrm{PCBT}_{21}$, and $\mathrm{PCBT}_{32}$.

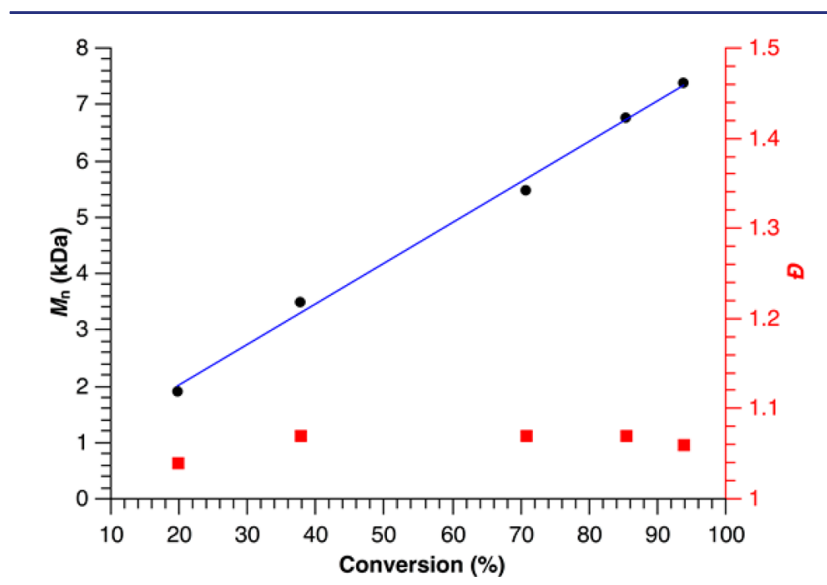

Figure 5. Plot of $M_{n}$ and $Ð$ versus monomer conversion for the polymerization of ( $R$ )-5 using TBD as the catalyst and 4methoxybenzyl alcohol as the initiator, obtained from SEC analyses from one of three runs; monomer/initiator/TBD ratio was 20:1:2.

monomeric product(s) from an initial ring-opening reaction. Characterization by ${ }^{1} \mathrm{H},{ }^{13} \mathrm{C}$, and ${ }^{31} \mathrm{P}$ NMR spectroscopies confirmed the ring opening had occurred and identified a single phosphorus environment (Figure S8). ${ }^{1} \mathrm{H}-{ }^{31} \mathrm{P} \mathrm{HMBC}$ analysis on the product isolated from unreacted (R)-5 indicated that only unimer $\mathbf{1 0}$ had formed (Figure S9), suggesting that the initial ring-opening reaction was more favorable at the $\mathrm{P}-\mathrm{OS}^{\prime}$ position. Further investigations on the regioselectivity during subsequent propagation steps during the ROP are ongoing.

The kinetics of ROP of ( $R$ )-5 were investigated by conducting three polymerizations simultaneously from stock solutions. In these experiments, (R)-5 and 4-methoxybenzyl alcohol (molar ratio of 20:1) were premixed in anhydrous dichloromethane, and the solution was divided into three portions, to each of which was added solutions of TBD (molar ratio to initiator of $2: 1$ ) in anhydrous dichloromethane. After the mixtures were allowed to stir for a predetermined amount of time, aliquots were quenched by the addition of acetic acid. The monomer conversions were determined by ${ }^{31} \mathrm{P}$ NMR (Figure S11), while the molecular weights and their distribution values were determined by size exclusion chromatography (SEC) calibrated with linear polystyrene standards using THF as the mobile phase. Attempts to determine absolute molecular weights from the light scattering detector SEC traces were unsuccessful due to the poor signal-to-noise ratio (Figure S10). The linearity of $M_{\mathrm{n}}$ versus monomer conversion (Figure 5) suggested that the number of macromolecules in the reaction system was constant during polymerization, up to $95 \%$ conversion, with $Ð$ less than 1.10 throughout the polymerization. Kinetic plots of $\ln \left([\mathrm{M}]_{0} /[\mathrm{M}]\right)$ versus time showed the ROP of (R)-5 to exhibit pseudo-first-order kinetics with a propagation rate constant of $k_{\mathrm{p}}=9.2 \times 10^{-5} \mathrm{~s}^{-1}$ (Figure 6),

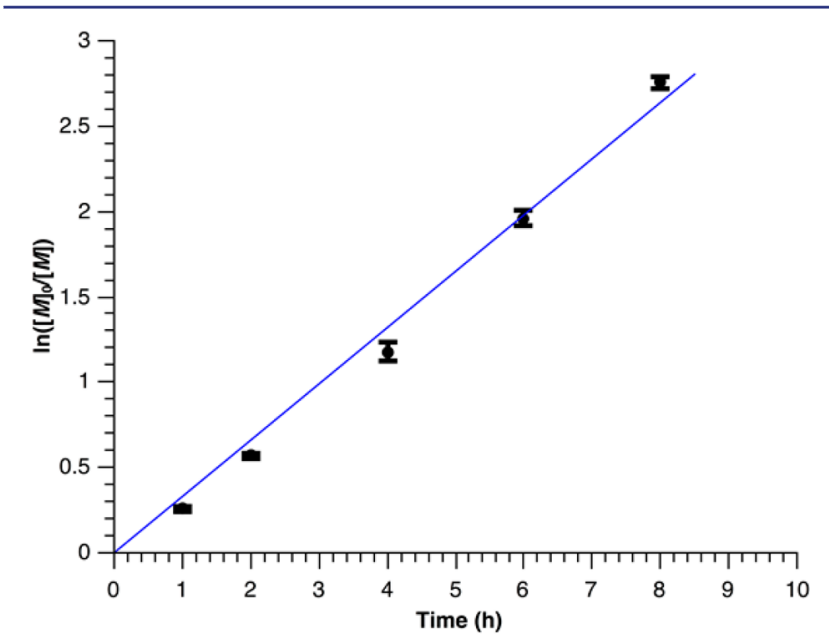

Figure 6. Kinetic plot of $\ln \left([\mathrm{M}]_{0} /[\mathrm{M}]\right)$ versus time, obtained from ${ }^{31} \mathrm{P}$ NMR data averaged over three runs. Linear regression equation: $y=$ $0.33 x ; R^{2}=0.98$

suggesting that the rate of initiation was greater than the rate of propagation. Even though $(\boldsymbol{R})-5$ was calculated to be more strained, the propagation rate was slower than those observed in the ROPs of five-membered cyclic hosphoesters (calculated as $k_{\mathrm{p}}=6.3 \times 10^{-3} \mathrm{~s}^{-1}$ from published data) ${ }^{33}$ under the same conditions.

A series of polymer 9 was synthesized in a variety of molecular weights by controlling the monomer to initiator ratio, as summarized in Table 3. The Waymouth and Hedrick groups conducted investigations of TBD-catalyzed ROP of cyclic esters, ${ }^{59}$ and found the reaction rates decrease with solvent polarity; that is, THF and DMF were observed to inhibit the catalytic activity of TBD due to hydrogen-bond

Table 3. Polymerization Results of (R)-5 with 4-Methoxybenzyl Alcohol and TBD at Ambient Temperature in Dichloromethane

\begin{tabular}{|c|c|c|c|c|c|c|c|c|}
\hline polymer & catalyst & M:I:catalyst (molar ratio) ${ }^{a}$ & time $(\mathrm{h})$ & conversion ( ${ }^{31} \mathrm{P}$ NMR) & $M_{\mathrm{n}}, \mathrm{Da}(\mathrm{SEC})^{b}$ & $Đ(\mathrm{SEC})^{b}$ & $M_{\mathrm{n}}, \mathrm{Da}(\text { theo })^{c}$ & $M_{\mathrm{n}}, \mathrm{Da}\left({ }^{1} \mathrm{H} \mathrm{NMR}\right)^{d}$ \\
\hline $\mathrm{PCBT}_{10}$ & TBD & $10: 1: 2$ & 6 & $96 \%$ & 3200 & 1.09 & 3800 & 3900 \\
\hline PCBT $_{21}$ & TBD & $20: 1: 2$ & 8 & $98 \%$ & 4800 & 1.06 & 7700 & 8200 \\
\hline PCBT $_{32}$ & TBD & $30: 1: 4$ & 24 & $95 \%$ & 6200 & 1.09 & 11000 & 12400 \\
\hline
\end{tabular}

${ }^{a}$ Initial monomer concentration for all entries was $0.25 \mathrm{M}$ in dichloromethane. ${ }^{b} M_{\mathrm{n}}$ (SEC) and $Ð$ (SEC) were measured by THF SEC calibrated using polystyrene standards. ${ }^{c} M_{\mathrm{n}}$ (theo) was calculated from the monomer to initiator ratio and corrected for the conversion. ${ }^{d} M_{\mathrm{n}}\left({ }^{1} \mathrm{H}\right.$ NMR) was calculated by comparing the ${ }^{1} \mathrm{H}$ NMR integration values for the resonance signals of the two aromatic protons ortho to the methoxy group of the 4methoxybenzyl initiated chain terminus $(6.89 \mathrm{ppm})$ with one alkenyl proton of the butylene side chain groups (5.85-5.72 ppm). 
interference. A similar phenomenon was expected in the ROP of $(R)-5$, due to the presence of two strong hydrogen-bond acceptors on the thymine unit; therefore, higher equivalents of TBD was required to efficiently drive the ROP as the stoichiometric ratio of $(\boldsymbol{R})-\mathbf{5}$ to initiator increased. The degrees of polymerization calculated from conversions determined by ${ }^{31} \mathrm{P}$ NMR spectroscopy agreed with those calculated from ${ }^{1} \mathrm{H}$ NMR chain end analyses, which compared the integration values for the resonance signals of the two aromatic protons ortho to the methoxy group of the 4-methoxybenzyl-initiated chain terminus $(6.89 \mathrm{ppm})$ with one alkenyl proton of the butylene side chain groups (5.85-5.72 ppm). Further analysis of PCBT $_{21}$ and PCBT $_{32}$ with electrospray ionization mass spectrometry (ESI-MS) suggested that chain end analyses provided more accurate molecular weight results than THF SEC (Figure S12).

Thymidine-derived 9 displayed thermal and physical properties distinct from previously reported polyphosphoesters as well as DNA. Polyphosphoesters synthesized from five-membered cyclic monomers exhibited low glass transition temperatures $\left(T_{\mathrm{g}}\right)$ of ca. $-50{ }^{\circ} \mathrm{C} .{ }^{33,39}$ In contrast, higher $T_{\mathrm{g}}$ values were measured for $9\left(50-55^{\circ} \mathrm{C}\right)$, likely due to the presence of a more rigid backbone. However, no glass transitions were detected for DNA samples, ${ }^{60}$ presumably due to the strong Coulombic repulsion between anionic chains that prevents long-range chain entanglement. Following treatment with cetyltrimethylammonium (CTMA) chloride to neutralize phosphates, a $T_{g}$ of $148{ }^{\circ} \mathrm{C}$ was reported for the DNACTMA powder. This high $T_{\mathrm{g}}$ value, even though not measured from a pure DNA sample, may be attributed to the strong hydrogen-bond interactions between base pairs. The lack of hydrogen-bond pairs in 9 not only decreased the $T_{\mathrm{g}}$ values, but also increased the hydrophobicity of the polymeric material in combination with the ester protection of anionic phosphates, making 9 insoluble in water but soluble in a variety of organic solvents (methanol, ethanol, chloroform, dichloromethane, dimethyl sulfoxide, DMF, and THF). The peak at ca. 270$280 \mathrm{~nm}$ in the circular dichroism spectrum acquired in dichloromethane (Figure S13) suggested that the stacking behavior of $N^{3}$-butenylthymine bases in $\mathbf{P C B T}_{20}$ might be similar to that of thymine bases in natural polythymidine in aqueous buffer. ${ }^{61}$

\section{CONCLUSIONS}

In summary, we have developed a novel, well-defined DNAanalogue system with $3^{\prime}, 5^{\prime}$-linkages from a six-membered cyclic phosphoester. Computational modeling was used to inform the rational design of stable alkene-functionalized thymidinederived polyphosphoesters. DFT calculations indicated that the ring strain energy of a six-membered cyclic phosphotriester of a 5,6-bicyclic ring system $(R)-3$ is ca. $6-7 \mathrm{kcal} / \mathrm{mol}$ greater than a six-membered monocyclic phosphotriester 1 , suggesting that such a structure could serve as a monomer for which ROP would be enabled. Therefore, thymidine was functionalized in the $N^{3}$-position and cyclized through the $3^{\prime}$ - and $5^{\prime}$-positions to afford a strained six-membered bicyclic phosphotriester monomer, and its organocatalyzed polymerization kinetics were explored. Interestingly, the DFT-calculated $1.35 \mathrm{kcal} / \mathrm{mol}$ higher energy of $(R)-5$, relative to its diastereomer $(S)-5$, led to its selective ability to undergo ROP, whereas $(S)-5$ was inert under the polymerization reaction conditions. To achieve the synthesis of this thermodynamically less stable diastereomer, (R)-5, the cyclization reaction was conducted under kinetically controlled conditions at $-78{ }^{\circ} \mathrm{C}$. ( $(R)-5$ was found to polymerize in a controlled manner $(\nexists<1.10)$ under TBDcatalyzed conditions initiated by 4-methoxybenzyl alcohol, and the chain length obtained during ROP could be predetermined by the stoichiometry of monomer to initiator ratios. The pseudo-first-order rate constant was measured to be $k_{\mathrm{p}}=9.2 \times$ $10^{-5} \mathrm{~s}^{-1}$. Overall, this work presents a novel and reliable synthetic methodology to obtain functional DNA analogues with unique properties and diverse potential applications.

\section{ASSOCIATED CONTENT}

\section{Supporting Information}

The Supporting Information is available free of charge on the ACS Publications website at DOI: 10.1021/jacs.7b01116.

Experimental procedures, spectroscopic data for all new compounds including ${ }^{1} \mathrm{H},{ }^{13} \mathrm{C}$, and ${ }^{31} \mathrm{P}$ NMR spectra, TGA, DSC, and details of computational chemistry (PDF)

\section{AUTHOR INFORMATION}

\section{Corresponding Author \\ *wooley@chem.tamu.edu \\ ORCID}

Karen L. Wooley: 0000-0003-4086-384X

Notes

The authors declare no competing financial interest.

\section{ACKNOWLEDGMENTS}

We gratefully acknowledge financial support from the National Heart Lung and Blood Institute of the National Institutes of Health as a Program of Excellence in Nanotechnology (HHSN268201000046C) and the National Science Foundation (CHE-1410272, CHE-1610311, and CHE-0541587). The Welch Foundation is gratefully acknowledged for support through the W. T. Doherty-Welch Chair in Chemistry, grant no. A-0001. We would like to thank the Laboratory for Molecular Simulation at Texas A\&M University for providing software and computer time. Use of the TAMU/LBMS, Dr. Bo Wang, and Dr. Doyong Kim are acknowledged for obtaining the mass spectra. We also acknowledge Mr. Steven D. Sorey at The University of Texas at Austin for assistance with the ${ }^{1} \mathrm{H}-{ }^{31} \mathrm{P}$ heteronuclear multiple bond correlation experiments. We thank Professor Tadhg P. Begley for access to the circular dichroism spectrometer.

\section{REFERENCES}

(1) Watson, J. D.; Crick, F. H. C. Nature 1953, 171, 737-738.

(2) Zuckermann, R.; Corey, D.; Schultz, P. Nucleic Acids Res. 1987, $15,5305-5321$.

(3) Karkare, S.; Bhatnagar, D. Appl. Microbiol. Biotechnol. 2006, 71, 575-586.

(4) Matsuda, S.; Fillo, J. D.; Henry, A. A.; Rai, P.; Wilkens, S. J.; Dwyer, T. J.; Geierstanger, B. H.; Wemmer, D. E.; Schultz, P. G.; Spraggon, G.; Romesberg, F. E. J. Am. Chem. Soc. 2007, 129, 1046610473.

(5) Maruyama, H.; Furukawa, K.; Kamiya, H.; Minakawa, N.; Matsuda, A. Chem. Commun. 2015, 51, 7887-7890.

(6) Malyshev, D. A.; Romesberg, F. E. Angew. Chem., Int. Ed. 2015, 54, 11930-11944.

(7) Taylor, A. I.; Pinheiro, V. B.; Smola, M. J.; Morgunov, A. S.; PeakChew, S.; Cozens, C.; Weeks, K. M.; Herdewijn, P.; Holliger, P. Nature 2015, 518, 427-430. 
(8) Anosova, I.; Kowal, E. A.; Dunn, M. R.; Chaput, J. C.; Van Horn, W. D.; Egli, M. Nucleic Acids Res. 2016, 44, 1007-1021.

(9) Horiya, S.; MacPherson, I. S.; Krauss, I. J. Nat. Chem. Biol. 2014, 10, 990-999.

(10) Friedman, A. D.; Kim, D.; Liu, R. Biomaterials 2015, 36, 110123.

(11) Diafa, S.; Hollenstein, M. Molecules 2015, 20, 16643-16671.

(12) Ibach, J.; Dietrich, L.; Koopmans, K. R. M.; Nöbel, N.; Skoupi, M.; Brakmann, S. J. Biotechnol. 2013, 167, 287-295.

(13) Meyer, A. J.; Garry, D. J.; Hall, B.; Byrom, M. M.; McDonald, H. G.; Yang, X.; Yin, Y. W.; Ellington, A. D. Nucleic Acids Res. 2015, 43, $7480-7488$.

(14) Hottin, A.; Marx, A. Acc. Chem. Res. 2016, 49, 418-427.

(15) Chen, T.; Hongdilokkul, N.; Liu, Z.; Adhikary, R.; Tsuen, S. S.; Romesberg, F. E. Nat. Chem. 2016, 8, 556-562.

(16) Michelson, A. M.; Todd, A. R. J. Chem. Soc. 1955, 0, 26322638

(17) Devine, K. G.; Reese, C. B. Tetrahedron Lett. 1986, 27, 55295532.

(18) Letsinger, R. L.; Ogilvie, K. K.; Miller, P. S. J. Am. Chem. Soc. 1969, 91, 3360-3365.

(19) Beaucage, S. L.; Caruthers, M. H. Tetrahedron Lett. 1981, 22, $1859-1862$

(20) Roy, B.; Depaix, A.; Périgaud, C.; Peyrottes, S. Chem. Rev. 2016, 116, 7854-7897.

(21) Kondo, K.; Iwasaki, H.; Ueda, N.; Takemoto, K.; Imoto, M. Makromol. Chem. 1968, 120, 21-26.

(22) Akashi, M.; Kita, Y.; Inaki, Y.; Takemoto, K. J. Polym. Sci., Polym. Chem. Ed. 1979, 17, 301-312.

(23) Khan, A.; Haddleton, D. M.; Hannon, M. J.; Kukulj, D.; Marsh, A. Macromolecules 1999, 32, 6560-6564.

(24) Marsh, A.; Khan, A.; Haddleton, D. M.; Hannon, M. J. Macromolecules 1999, 32, 8725-8731.

(25) Spijker, H. J.; van Delft, F. L.; van Hest, J. C. M. Macromolecules 2007, 40, 12-18.

(26) McHale, R.; O’Reilly, R. K. Macromolecules 2012, 45, 76657675

(27) Pradere, U.; Garnier-Amblard, E. C.; Coats, S. J.; Amblard, F.; Schinazi, R. F. Chem. Rev. 2014, 114, 9154-9218.

(28) Wang, Y.-C.; Yuan, Y.-Y.; Du, J.-Z.; Yang, X.-Z.; Wang, J. Macromol. Biosci. 2009, 9, 1154-1164.

(29) Zhang, X.; Jones, G. O.; Hedrick, J. L.; Waymouth, R. M. Nat. Chem. 2016, 8, 1047-1053.

(30) Hong, M.; Chen, E. Y.-X. Nat. Chem. 2016, 8, 42-49.

(31) Iwasaki, Y.; Yamaguchi, E. Macromolecules 2010, 43, 26642666.

(32) Kadota, J.; Pavlović, D.; Desvergne, J.-P.; Bibal, B.; Peruch, F.; Deffieux, A. Macromolecules 2010, 43, 8874-8879.

(33) Zhang, S.; Li, A.; Zou, J.; Lin, L. Y.; Wooley, K. L. ACS Macro Lett. 2012, 1, 328-333.

(34) Clément, B.; Grignard, B.; Koole, L.; Jérôme, C.; Lecomte, P. Macromolecules 2012, 45, 4476-4486.

(35) Dove, A. P. ACS Macro Lett. 2012, 1, 1409-1412.

(36) Lim, Y. H.; Heo, G. S.; Cho, S.; Wooley, K. L. ACS Macro Lett. 2013, 2, 785-789.

(37) Steinbach, T.; Ritz, S.; Wurm, F. R. ACS Macro Lett. 2014, 3, 244-248.

(38) Sun, C.-Y.; Dou, S.; Du, J.-Z.; Yang, X.-Z.; Li, Y.-P.; Wang, J. Adv. Healthcare Mater. 2014, 3, 261-272.

(39) Zhang, S.; Zou, J.; Zhang, F.; Elsabahy, M.; Felder, S. E.; Zhu, J.; Pochan, D. J.; Wooley, K. L. J. Am. Chem. Soc. 2012, 134, 1846718474.

(40) Kaluzynski, K.; Libisowski, J.; Penczek, S. Macromolecules 1976, 9, 365-367.

(41) Kaluzynski, K.; Penczek, S. Makromol. Chem. 1979, 180, 22892293.

(42) Lapienis, G.; Pretula, J.; Penczek, S. Macromolecules 1983, 16, 153-158.
(43) Kałuźynski, K.; Libiszowski, J.; Penczek, S. Makromol. Chem. 1977, 178, 2943-2947.

(44) Łapienis, G.; Penczek, S. J. Polym. Sci., Polym. Chem. Ed. 1977, $15,371-382$.

(45) Kluger, R.; Taylor, S. D. J. Am. Chem. Soc. 1990, 112, 66696671.

(46) Aksnes, G.; Bergesen, K. Acta Chem. Scand. 1966, 20, 25082514.

(47) Dudev, T.; Lim, C. J. Am. Chem. Soc. 1998, 120, 4450-4458.

(48) Taylor, S. D.; Kluger, R. J. Am. Chem. Soc. 1992, 114, 30673071.

(49) Gerlt, J. A.; Westheimer, F. H.; Sturtevant, J. M. J. Biol. Chem. 1975, 250, 5059-5067.

(50) Geise, H. J. Recl. Trav. Chim., Pays-Bas 1967, 86, 362-370.

(51) Bodkin, C.; Simpson, P. J. Chem. Soc. D 1969, 829-830.

(52) Bentrude, W. G.; Hargis, J. H. J. Am. Chem. Soc. 1970, 92, $7136-7144$

(53) Hall, L. D.; Malcolm, R. B. Can. J. Chem. 1972, 50, 2092-2101.

(54) Mosbo, J. A.; Verkade, J. G. J. Org. Chem. 1977, 42, 1549-1555.

(55) Gregory, G. L.; Hierons, E. M.; Kociok-Köhn, G.; Sharma, R. I.; Buchard, A. Polym. Chem. 2017, 8, 1714-1721.

(56) Gregory, G. L.; Kociok-Köhn, G.; Buchard, A. Polym. Chem. 2017, 8, 2093-2104.

(57) Pereira, M. S.; Murta, B.; Oliveira, T. C. F.; Manfredi, A. M.; Nome, F.; Hengge, A. C.; Brandao, T. A. S. J. Org. Chem. 2016, 81, $8663-8672$

(58) Jain, H. V.; Kalman, T. I. Bioorg. Med. Chem. Lett. 2012, 22, 4497-4501.

(59) Pratt, R. C.; Lohmeijer, B. G. G.; Long, D. A.; Waymouth, R. M.; Hedrick, J. L. J. Am. Chem. Soc. 2006, 128, 4556-4557.

(60) Jin, J.; Grote, J. Materials Science of DNA; CRC Press: Boca Raton, FL, 2011.

(61) Greve, J.; Maestre, M. F.; Levin, A. Biopolymers 1977, 16, 14891504. 